\title{
Revisiting Characteristics of Ionic Liquids: A Review for Further Application Development
}

\author{
Rusen Feng $^{1,2}$, Dongbin Zhao $^{1 *}$, Yongjun Guo ${ }^{1}$ \\ ${ }^{1}$ State Key Lab of Oil and Gas Reservoirs Geology and Exploration, Southwest Petroleum University, Chengdu, China; ${ }^{2}$ School of \\ Chemistry and Chemical Engineering, Southwest Petroleum University, Chengdu, China. \\ Email: zhao.dongbin@yahoo.com
}

Received January $15^{\text {th }}, 2010$; revised March $8^{\text {th }}, 2010$; accepted March $10^{\text {th }}, 2010$.

\begin{abstract}
In literature concerning ionic liquid (IL) applications, the commonly accepted properties of ionic liquids are frequently mentioned. For example, ionic liquids are described as possessing immeasurably low vapor pressure, being "green material", non-coordinating, physically and chemically stable, and non-toxic, to name a few. However, all these descriptions are deemed "not exact" [1] as intensive research on ionic liquid properties continues. This review highlights the most recent developments in IL chemistry where the "well-known" description of IL properties sometimes proves to be inaccurate. However, in the authors' opinion, all these new research developments concerning ionic liquid properties serve to update knowledge on the typical physical and chemical properties of ILs, which is significant to both theoretical research and industrial applications. This review presents an opportunity to understand IL through a more complete and accurate view. It seeks to pave the way for further studies on IL application in various fields.
\end{abstract}

Keywords: Ionic Liquids, Functionalized Ionic Liquids, Volatility, Polarity, Green Chemistry

\section{Introduction}

Scientific and technical research on ionic liquid (IL) application has progressed over the last 20 years. Interest has been derived from ILs' unique advantageous properties, such as non-volatility, versatile solubility, and stability, to name a few. These properties present ILs as a promising alternative to environmentally undesirable volatile organic solvents, especially chlorinated hydrocarbons. Successful industrial processes using ionic liquids appear to confirm such advantages [2].

Another important feather on the cap of ILs is the ability of their molecular structure to be tailored according to application requirements. This has spurred the rise of task-specific ionic liquids, or the so-called functionalized ionic liquids [3-5].

Existing studies on ILs, especially the earlier ones, reiterated the following advantageous properties:

1) No measurable vapor pressure or non-volatility

2) Low toxicity

3) High polarity

4) Non-coordination

5) Physical and chemical stability

The above-mentioned description appeared at a time when only limited kinds of ionic liquids were available, especially those based on imidazolium salts. In-depth investigations were not carried out. Nevertheless, as research progressed and a number of new ILs were synthesized, the said properties were proven to be non-standard.

Various results obtained from newer research works offered counterexamples to the said properties. For example, IL vapor pressure can now be measured and ILs can be distilled. Further, the toxicity tests of commonly used ILs in bioassays prove that they are considerably toxic. Furthermore, the commonly used "stable" 1-ethyl3-methylimidazolium bis(trifluoromethylsulfonyl)imide ([emim] $\left[\mathrm{Tf}_{2} \mathrm{~N}\right]$ ) was even tested as a propellant for space shuttle. Based on these, the authors conclude that the traditional description has been rendered incomplete and inappropriate. In addition, the IL varieties that trigger property change are, to a certain extent, ignored and not realized systematically.

To date, there is a significant number of high-quality reviews on IL research activities, from the early ones that generally focused on catalysis [6-13], to current detailed descriptions of specified applications such as coordination chemistry [14], physicochemical properties [15], analytical chemistry [16], polymer materials [17], fluorine chemistry [18], and nanotechnology [19]. All these reviews contribute largely to the rapid rise and stimulation of research interest on ILs. 
This review attempts to highlight the new findings concerning ionic liquid properties, specifically those indicating that the ILs" "well-known" descriptions should be updated and even corrected. The authors believe that a careful recognition of IL properties based on recent discoveries is essential to research and application. Instead of nullifying the unique value of ionic liquids, this will provide an opportunity to explore new avenues for research and application. Without a doubt, a more complete and accurate understanding of IL properties will be beneficial for further studies concerning these "magic" liquids.

\section{Can Ionic Liquids be Distilled?}

"Negligible", "immeasurable", "extremely low", "vanishingly small", and "virtually nonexistent" are among the most common descriptions ascribed to vapor pressure of ionic liquids. It was therefore logical to assume that ionic liquids are non-volatile and impossible to distill, especially since they are composed completely of ions [20].

Early investigations of ionic liquids' thermal properties using thermogravimetric analysis (TGA) [21] proved that they possessed minimal vapor pressure up to their thermal decomposition temperature. This property is considered an advantage when applied to the distillation process because the azeotrope formation between the solvent and products does not occur. In addition, this charac teristic is expected to ease manipulation and purification, and facilitate multiphasic application and recycling [22]. Vapor pressure research related to ILs was almost refined in the binary or multimixed system of ILs and other volatile liquids [23-29]. There were reports on the theoretical estimation of ILs' thermodynamic properties, including the calculation of vapor pressures [30-32].

However, this feature led to certain limitations such as problems in distilling ionic liquids to achieve extreme purity or the almost-impossible use of the ionic liquids in the gas phase. One exception is the protic ionic liquids written as $[\mathrm{HC}]^{+}[\mathrm{A}]^{-}$, which can be vaporized like equilibrium forming [C][HA], which are both volatile [33] (Scheme 1). However, the reverse protic transfer is found recently can be controlled by changing cation type, for example, superbase cations by which the thermal stability is greatly enhanced [34].

Information purporting that "ionic liquid cannot be distilled" and "their vapor pressure cannot be measured" has been nullified only recently. A report on one-stage

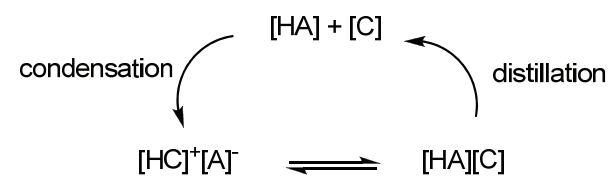

Scheme 1. Distillation process of protic ionic liquids distillation of imidazolium ionic liquid of $\left[\mathrm{Tf}_{2} \mathrm{~N}\right]$ anion under reduced pressure at moderate temperature was published [35] The authors used experimental surface tension and density measurement, as well as Eötvos or Guggenheim empirical equations, to estimate the critical points related to the IL's normal boiling points. According to the study's results, measuring ILs' vapor pressure is possible, owing to a wide window of possible experimental working temperature of obtained boiling point data. Ionic liquids, $\left[\mathrm{C}_{10} \mathrm{mim}\right]\left[\mathrm{Tf}_{2} \mathrm{~N}\right]$, and $\left[\mathrm{C}_{12} \mathrm{mim}\right]\left[\mathrm{Tf}_{2} \mathrm{~N}\right]$ were found to be readily distilled under $450 \mathrm{~K}$ and $1 \mathrm{~Pa}$ pressure. Shortly after, the experimental vapor pressure data were measured via the Knudsen method. Within the temperature range of $458-517 \mathrm{~K}$, the relationship between vapor pressure and temperature was obtained [36, 37].

More recently, studies proved that a broader series of ionic liquid of $\left[\mathrm{Tf}_{2} \mathrm{~N}\right]$ anion could be distilled at 473-573 $\mathrm{K}$ under low pressure using the Kugelrohr apparatus [38]. Protic ionic liquids of trifluoroacetate or formate anion, however, can be distilled more easily using the standard method under normal pressure and temperature [39]. As mentioned above, the Lewis acidity/basicity is believed to produce the main effect on protic ionic liquids' volatile property [33].

From assuming a "non-distillable" property to discovering a large number of distillable ionic liquids, it is needless to predict that the non-volatile advantage of ionic liquids is diminishing. However, all these observations broaden the field of ionic liquid property research and may lead to wider applications.

\section{Are Ionic Liquids Really that Green?}

Because of ionic liquids" "immeasurably" low vapor pressure under normal conditions [10], they are considered as "greener" solvents rather than volatile organic compounds (VOCs) that emit pollution to the atmosphere. This "greenness", however, merely satisfies certain parts of the 12 principles of Green Chemistry [40] if ionic liquids are used in chemical processes. Unfortunately, this has been misinterpreted as possessing broader green properties such as low toxicity and biodegradability. It should be noted that a considerable number of precursors to ionic liquids were labeled as toxic and environmentally hazardous, and the toxicity and biodegradability of ionic liquids generated thereof require further investigation.

Looking into the hazards involved in using ionic liquids was not attempted until 2003 [41]. The authors of the study theoretically used the structure-activity relationship to discuss the toxicity and ecotoxicity of a selection of commonly used ILs. The direct toxicity analyses of ILs followed thereafter, mainly using bacteria or cells as targets. Examples included vibrio fischeri and WST-1 cell $[42,43]$, human tumor cell line HeLa [44], latic acidproducing bacteria as lactobacillus rhamnosus $[45,46]$, 
Escherichia coli, Pichia pastoris and Bacillus cereus [47], Caenorhabditis elegans [48], and acetylcholinesterase [49].

The acute toxic effects of ILs on various high forms of organisms, plant or animals, were likewise tested; these included algae,[50] Daphnia magan [51], zebrafish ( $d a-$ nio rerio) [52], rabbits [53], fresh water snails [54], and zebra mussel (Dreissena polymorpha) [55]. Different ionic liquids displayed diverse toxicity to the bio subjects used in the said research. In addition, various methodologies were developed and investigated for better understanding of this toxicity issue, such as the quantitative structure-property relationship modeling [56], lipophilicity, and metabolic pathway prediction of ILs [57].

Despite various efforts to discover whether or not ionic liquids are toxic, as well as the possible extent of toxicity, researchers have yet to arrive at a clear answer because of acceptors' and ILs' variability. In certain reports, for example, compared with traditional solvents, imidazolium-based ionic liquids are reportedly more toxic to microorganisms [43]. However, a number of reports claim that the lactic acid-producing bacterium still grows faster in the presence of imidazolium-based ionic liquids than in hexane [45]. Certain primitive trends on the commonly used ionic liquids were found, such as an increase in toxicity of aquatic organisms as the number of nitrogen atoms in the cation increases [56].

The biodegradability of ILs are similarly an object of research interest, and the Closed Bottle Test (OECD 301D) is commonly used to administer the biodegradability test. At present, the biodegradability of traditional non-functionalized ILs, such as those based on $\left[\mathrm{C}_{4} \mathrm{mim}\right]^{+}$, are hard to be biotic-degraded [58]; and the abiotic degradation is found to be impossible for $\left[\mathrm{C}_{4} \mathrm{mim}\right]\left[\mathrm{BF}_{4}\right][59]$.

Despite the fact that many ionic liquids exhibit toxicity and create a negative impact on the environment, it should be remembered that certain parts of toxic ILs are not necessarily indicating that all the ILs are toxic. Furthermore, ionic liquids in principle can be modified to be non-toxic. Previous studies have reported that ILs can be obtained from biodegradable and renewable resources [60-68]. With infinite possibilities for designing ionic liquids, the authors of this study are optimistic that IL can be designed to be non-toxic, readily degradable, and even edible. For example, the following shown ionic liquids can be classified as "readily biodegradable" [69] (Scheme 2). It is also possible to design ionic liquid possessing a toxicity level that serves a specific need. For instance, ionic liquids extraction of Para Red and Sudan dyes from chilli powder, chilli oil and food additive combined with high performance liquid chromatography has been reported very recently [70], which shows application potentials of ILs in food industries, especially in analytical applications [71,72].<smiles>[X]c1ccccc1CC(=O)OCC</smiles><smiles>[X][n+]1cccc(C(=O)OCCCC)c1</smiles>

Scheme 2. Biodegradable pyridinium ionic liquids

Until now, the toxicity related investigation is still a hot topic concerning safety issue of ionic liquids, among which detailed research activities are carried out continuously [73-75]. A Agar Diffusion Test has also been developed for clarification of biocompatibility of water-miscible ionic liquids [76].

\section{Do Ionic Liquids have high Polarity?}

Polarity is a physical property of compounds related to other physical properties such as melting and boiling points, solubility, and intermolecular interactions [77]. Ionic liquids have been considered as polar solvents, such as those suitable for charged compounds, possibly because of their ionic nature.

The first polarity investigation of ionic liquids using the solvatochromic dye method emerged in 2000, postulating that imidazolium-based ILs possess a polarity similar to lower alcohols [78]. Various methods were subsequently developed to determine the polarity of ILs, such as fluorescent dye method [79,80], EPR spectroscopy [81], 2-nitrocyclohexanone tautomerism method [82], microwave spectroscopy [83], FT-IR spectroscopic probe $\left(\mathrm{Fe}(\mathrm{CO})_{5}\right)$ [84], and FT-IR combined with density functional calculations (DFT) [85]. These different methods resulted in accordance, but a definitive standard has not been established for ionic liquid polarity. However, all these tests revealed that ILs were not as polar as expected. On the contrary, they demonstrated considerably low polarity [86].

The polarity of ILs is responsible for their ability to dissolve solutes. The solubility of many non-polar substances in ILs, including hydrogen [87], carbon monoxide [88], and fullerene [89], has been tested. It has been found that hydrogen and carbon monoxide possessed solubility that is quite higher than what was initially expected. In the case of ionic liquid of cation with long alkyl chain, the solubility of $\mathrm{H}_{2}$ is higher than non-polar organic solvents like benzene. $\mathrm{C}_{60}$ can likewise be dissolved in ILs at concentration of up to $0.1 \mathrm{mg} / \mathrm{ml}$. There are as well reports on the $\mathrm{CH}_{4}$ dissolution into low- polarity designed ILs [90].

It is reasonable to state that ILs can dissolve not only polar solutes or charged solute via ionic liquid structure design, but also various non-polar compounds. However, a more comprehensive investigation on solute-solvent interactions has yet to be performed. 


\section{Can Ionic Liquids Coordinate?}

A decade ago, ILs were generally perceived as non-coordinating, which implied that their anions were noncoordinating as well [6-13]. Various scientific publications have postulated that ILs were "poorly coordinating" or "weakly coordinating" [91]. However, recent reports have claimed that ILs are indeed coordinating [92-94].

The coordinating ability is a tendency to donate electron(s) to form a chemical bond [95]. In traditional imidazolium IL systems, the cationic part displays minor coordinating ability, thus the coordinating abilities are determined by the anionic part [96]. The chloride or bromide displays strong coordinating abilities, and this is reflected in many crystallographic studies as well as NMR and IR studies [97,98]. For other anions, however, especially those that reduce the viscosities and melting points of ionic liquids (e.g., $\left[\mathrm{BF}_{4}\right]^{-},\left[\mathrm{SO}_{3} \mathrm{CF}_{3}\right]^{-}$), there is little evidence obtained from X-ray crystallography. Delocalization of the negative charge within the anionic core structure (e.g., O-S-N-S-O for $\left[\mathrm{Tf}_{2} \mathrm{~N}\right]^{-}$, O-S-O for $\left.\left[\mathrm{SO}_{3} \mathrm{CF}_{3}\right]^{-}\right)$accounts for the weak columbic attraction between the anion and the weakly acidic organic cations (i.e., low lattice energy and low melting points). They are assumed to be non-coordinating because the negative charge is highly delocalized over electron-negative fluorine atoms.

However, as the chemistry of ILs continued to advance, there rose evidences that even the above-mentioned ILs demonstrate coordinating abilities towards main group metals and transition metals. Recent studies of several commonly used ILs through in situ re-crystallization suggest that the intermolecular $\mathrm{C}-\mathrm{H} \cdots \mathrm{F}$ interactions are likewise commonly present in these ILs. The hydrogen bonding network differs depending on the anions, from $\left[\mathrm{BF}_{4}\right]^{-},\left[\mathrm{PF}_{6}\right]^{-}$, to $\left[\mathrm{Tf}_{2} \mathrm{~N}\right]^{-},\left[\mathrm{SO}_{3} \mathrm{CF}_{3}\right]^{-}$[99]. Prior to this work, $\mathrm{C}-\mathrm{H} \cdots \mathrm{F}$ interactions were equally found in other ionic liquids with $\left[\mathrm{SO}_{3} \mathrm{CF}_{3}\right]$ anion [100]. From the fact that these ILs can donate electrons to $\mathrm{H}$ atoms, it is reasonable to imply that they can likewise coordinate to Lewis acidic metals and exhibit a coordinating property.

The coordinating abilities of ILs have been utilized in various processes as well. An interesting example is that $\left[\mathrm{BF}_{4}\right]$ anion exhibits a coordinating ability towards $\mathrm{BF}_{3}$; this process has been successfully used in the storage and

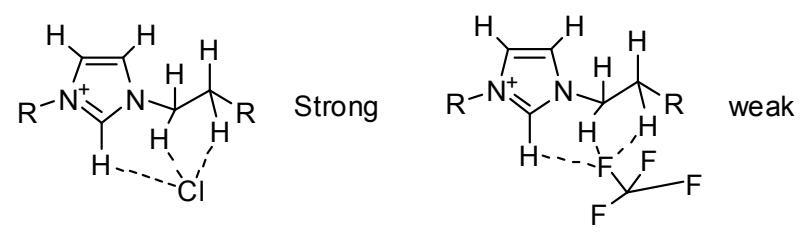

Scheme 3. Anion coordination of imidazolium ionic liquids transport of highly toxic gases such as $\mathrm{BF}_{3}[101,102]$. It is believed that the fluorine atoms in the anion can interact as donor to the boron atom of the $\mathrm{BF}_{3}$ molecule, and a Lewis acid and base complex can be formed through this process. In another example, the $\left[\mathrm{CH}_{3} \mathrm{BF}_{3}\left(\mathrm{CH}_{2}\right)_{2} \mathrm{CN}\right]$ anion displays coordination ability towards potassium [103] (Scheme 3).

The coordinating abilities of $\left[\mathrm{PF}_{6}\right]$ anions was investigated and compared with the molecular solvents dichloromethane [91]. Owing to the coordinating behavior of the $\left[\mathrm{PF}_{6}\right]$ anion, the IL of $\left[\mathrm{PF}_{6}\right]^{-}$can be successfully used as both catalyst and solvent for olefin polymerization and ethane oligomerization to higher $\alpha$-olefins by cation catalysts [91]. The mechanism is believed to be the coordination of $\mathrm{F}$ atoms in the $\left[\mathrm{PF}_{6}\right]$ anion, which activates the olefin. Polymerization can thus be induced in the presence of a nickel catalyst (Scheme 4).

Anion $\left[\mathrm{Tf}_{2} \mathrm{~N}\right]$ has been frequently used as ionic liquid anion to reduce IL viscosity; this can improve ionic conductivity as well. To date, its rich coordination chemistry remains unexplored. However, recent studies suggest that $\left[\mathrm{Tf}_{2} \mathrm{~N}\right]$ is a versatile coordinating anion that can interact with transition metals in various modes. For example, $\mathrm{N}$-methyl-N-propylpyrrolidinium bis (triflouromethanesufonyl) imide [92] reacts with $\mathrm{YbI}_{2}$, creating a complex in which the $\left[\mathrm{Tf}_{2} \mathrm{~N}\right]$ anions coordinate with the $\mathrm{Yb}$ center in a chelating mode using the two oxygen atoms as donors. The cation was included in the final structure to balance the charge. The $\mathrm{O}-\mathrm{Yb}$ distances were between 241.0 to 251.7 $\mathrm{pm}$, the latter being the longest among all complexes with $\mathrm{Yb}-\mathrm{O}$ bonds. All the ligands showed cissoids conformation with respect to the $\mathrm{CF}_{3}$ groups (Scheme 5).

With transition metals, $\mathrm{Ti}, \mathrm{Fe}, \mathrm{Ru}$, and $\left[\mathrm{Tf}_{2} \mathrm{~N}\right]$ anions can use its donor $\mathrm{O}$ or $\mathrm{N}$ to coordinate metal centers forming $\eta^{2}-\mathrm{O}, \mathrm{O}$, or $\eta^{2}-\mathrm{O}, \mathrm{N}$, chelating or $\eta^{1}-\mathrm{N}, \eta^{1}-\mathrm{O}$, mono-complexes [104,105] (Scheme 6).

Ionic liquids appear to coordinate from birth and it should be noted that ionic liquids can be designed to coordinate deliberately by incorporating coordination groups. Ionic liquids containing various coordinating functionalities that can coordinate to main group metals and transition metals were reported. ${ }^{i}$ This has evoked a change in ionic liquid chemistry. These functionalized ionic liquids have been successfully used in catalysis, coordination polymers, and gas-absorption. This aspect had been reviewed previously [4]. Apart from the cation coordinating ILs, a number of ILs bearing coordination groups in the anion have likewise been reported [106].

\section{Stable Versus Energetic}

The stability of a very limited number of ionic liquids has been misleadingly accorded to all ionic liquids. In fact, the earliest examples based on $\left[\mathrm{AlCl}_{4}\right]$ anions were extremely air-sensitive, so much so that their application has been very limited $[107,108]$. 
<smiles>FB(F)B(F)P[SbH2]</smiles><smiles></smiles><smiles>C=CP(F)(F)(F)F</smiles>

Scheme 4. Coordination of $\mathrm{BF}_{4}, \mathrm{R}-\mathrm{BF}_{3}$ and $\mathrm{PF}_{6}$<smiles>CCC[N+]1(C)CCCC1</smiles>

Scheme 5. Yb complex with $\left[\mathrm{Tf}_{2} \mathrm{~N}\right]$ anion<smiles>O=S(=O)(N(C(F)(F)F)S(=O)(=O)C(F)(F)F)C(F)(F)F</smiles><smiles>O=S(=O)(NS(=O)(=O)C(F)(F)F)C(F)(F)F</smiles><smiles>O=S1(=O)N[SH](=O)(C(F)(F)F)O[I]O1</smiles><smiles>[R1]NS(=O)(=O)C(F)(F)S(=O)(=O)C(F)(F)F</smiles>

Scheme 6. Coordination modes of $\left[\mathrm{Tf}_{2} \mathrm{~N}\right]$ anion with transition metals, $\mathrm{M}=\mathrm{Fe}$, Ti, $\mathrm{Ru}$

The stable generation ILs represented by 1, 3-dialkyl imidazolium salts with $\left[\mathrm{BF}_{4}\right],\left[\mathrm{PF}_{6}\right]$ anions are indeed thermally stable compounds that will not decompose below $300^{\circ} \mathrm{C}$. The high thermal stability has been an ad-

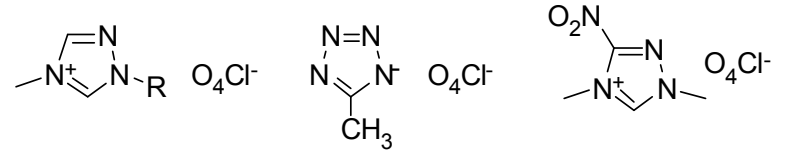

Scheme 7. Energetic ionic liquids

vantage in many applications. However, there have been reports alleging that they decompose when heated in the presence of water, thus emitting HF [109].

Detailed stability studies on ILs have been extensively reported and reviewed [66,110,111]. Imidazolium-based ILs are not stable under basic conditions. In the presence of strong bases, they decompose to produce Manichelimination products [112]. Phosphonium ILs are more inert against strong bases, so that reactions using strong bases, such as Grignard reagents, can be carried out among phosphonium ILs. The results, however, are not better than molecular solvents such as THF [113]. In fact, stability can also been obtained through ionic liquid structure design. For example, a series of geminal dicationic ionic liquids were reported, among which the stable range can be -4 to $400^{\circ} \mathrm{C}$ [114].

Meanwhile, ILs can be designed as unstable yet energetic [100,115-119]. For example, Shreeve et al. have designed and synthesized a series of triazolium, tetraazolium- based ILs, especially those with $\left[\mathrm{ClO}_{4}\right]$ and $\left[\mathrm{NO}_{3}\right]$ anions (Scheme 7) that can be exposed at considerably low temperature so that they can be used as energetic materials [120-123]. These works have been covered in a recent review [124]. It is important to emphasize that in general, organic nitrates and perchlorates are potentially explosive, especially when rigorously dried. Although no problems have been reported to date, care should be taken at all times when handling these. It has been reported that a large number of ILs, including commercially available ILs, are combustible owing to the positive heat formation, oxygen content, and decomposition products [125].

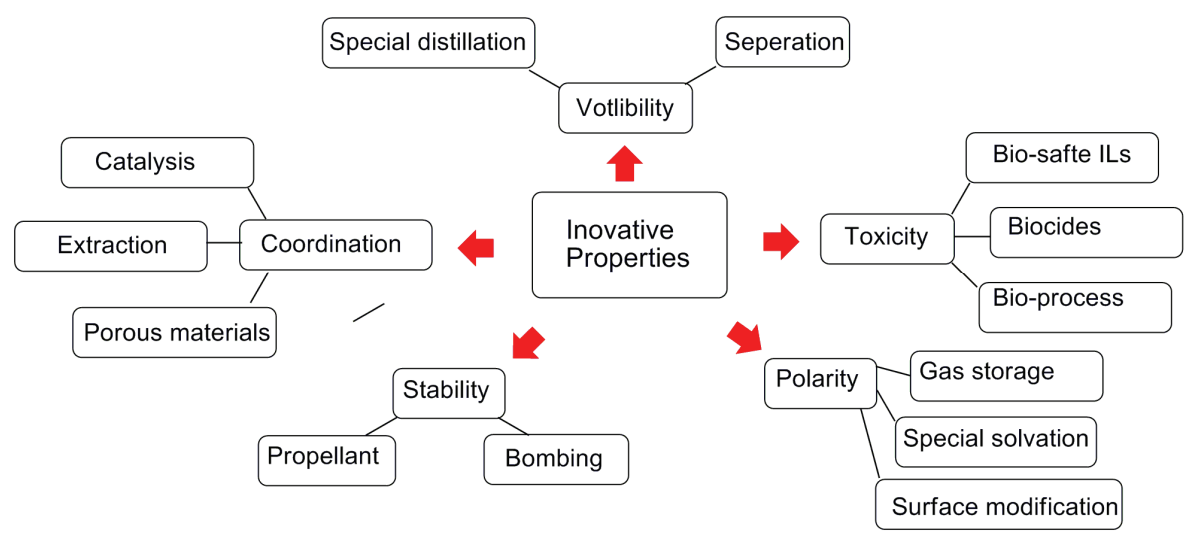

Figure 1. Discovery of innovative properties of IL-inducing novel applications 
It is important to note that there is a significant number of functionalized ILs that are now available, though their stability has not been routinely investigated.

\section{Perspectives}

This review aims to arrive at a gradual understanding of the following knowledge on IL properties, which is continuously being updated:

1) Some ionic liquids can be readily distilled.

2) Some ionic liquids are proven toxic and environmentally hazardous.

3) Some ionic liquids are low polar.

4) Ionic liquids are normally coordinating.

5) Ionic liquid stability can be controlled through molecular design.

All these changes demonstrate a quiet but ongoing transformation in our understanding of IL properties. Instead of arresting the development of IL applications, the realization and deeper understanding of IL properties can lead to innovation and application to more fields, as illustrated in Figure 1.

\section{Acknowledgements}

This work is supported by the National Basic Research Program, or 973 Program, of P. R. China (project number: 2005CB221300).

\section{REFERENCES}

[1] M. Deetlefs and K. R. Seddon, "Ionic Liquids: Fact and Fiction," Chimica oggi, Vol. 24, No. 2, 2006, pp.16-23.

[2] H. Olivier-Bourbigou and F. Hughes, "Green Industrial Applications of Ionic Liquids," Kluwer Academic Publishers, Dordrecht, 2003, pp.67.

[3] J. H. Davis Jr., "Task-Specific Ionic Liquids," Chemistry Letters, Vol. 33, No. 9, 2004, pp. 1072-1077.

[4] Z. Fei, T. J. Geldbach, D. Zhao, et al., "From Dysfunction to Bis-function: On the Design and Applications of Functionalised Ionic Liquids," Chemistry a European Journal, Vol. 12, No. 8, 2006, pp. 2122-2130.

[5] S.-g. Lee, "Functionalized Imidazolium Salts for TaskSpecific Ionic Liquids and their Applications," Chemical Communications, 2006, pp. 1049-1063.

[6] K. R. Seddon, "Ionic Liquids for Clean Technology," Journal of Chemical Technology and Biotechnology, Vol. 68, No. 4, 1997, pp. 351-356.

[7] T. Welton, "Room-Temperature Ionic Liquids. Solvents for Synthesis and Catalysis," Chemical Reviews, Vol. 99, No. 8, 1999, pp. 2071-2083.

[8] R. Sheldon, "Catalytic Reactions in Ionic Liquids," Chemical Communications, 2001, pp. 2399-2407.

[9] C. M. Gordon, "New Developments in Catalysis Using Ionic Liquids," Applied Catalysis A: General, Vol. 222, No. 1-2, 2001, pp. 101-117.
[10] M. J. Earle and K. R. Seddon, "Ionic Liquids. Green Solvents for the Future," Pure and Applied Chemistry, Vol. 72, No. 7, 2000, pp. 1391-1398.

[11] J. Dupont, R. F. de Souze and P. A. Z. Suarez, "Ionic Liquid (Molten Salt) Phase Organometallic Catalysis," Chemical Reviews, Vol. 102, No. 10, 2002, pp. $3667-$ 3691.

[12] H. Olivier-Bourbigou and L. Magna, "Ionic Liquids: Perspectives for Organic and Catalytic Reactions," Journal of Molecular Catalysis A-Chemical, Vol. 182, No. 1, 2002, pp. 419-437.

[13] D. Zhao, M. Wu, Y. Kou, et al., "Ionic Liquids: Applications in Catalysis," Catalysis Today, Vol. 74, 2002, pp. 157.

[14] V. A. Cocalia, K. E. Gutowski and R. D. Rogers, "The Coordination Chemistry of Actinides in Ionic Liquids: A Review of Experiment and Simulation," Coordination Chemistry Reviews, Vol. 250, No. 7-8, 2006, pp. 755-764.

[15] H. Weingärtner, "Understanding Ionic Liquids at the Molecular Level: Facts, Problems, and Controversies," Angewandte Chemie International Edition, Vol. 47, No. 4, 2008, pp. 654-670.

[16] M. Koel, "Ionic Liquids in Chemical Analysis," Critical Reviews in Analytical Chemistry, Vol. 35, No. 3, 2005, pp. 177-192.

[17] P. Kubisa, "Ionic Liquids in the Synthesis and Modification of Polymers," Journal of Polymer Science Part A: Polymer Chemistry, Vol. 43, No. 20, 2005, pp. 46754683.

[18] H. Xue, R. Verma and J. M. Shreeve, "Review of Ionic Liquids with Fluorine-Containing Anions," Journal of Fluorine Chemistry, Vol. 127, No. 2, 2006, pp. 159-176.

[19] M. Antonietti, D. Kuang, B. Smarsly, et al., "Ionic Liquids for the Convenient Synthesis of Functional Nanoparticles and Other Inorganic Nanostructures," Angewandte Chemie International Edition, Vol. 43, No. 38, 2004, pp. 4988-4992.

[20] K. R. Seddon, "Room-Temperature Ionic Liquids: Neoteric Solvents for Clean Catalysis," Kinetics and Catalysis, Vol. 37, No. 5, 1996, pp. 693-697.

[21] H. L. Ngo, K. LeCompte, L. Hargens, et al., "Thermal Properties of Imidazolium Ionic Liquids," Thermochimica Acta, Vol. 97, 2000, p. 357.

[22] H. Zhao, "Review: Current Studies on Some Physical Properties of Ionic Liquids," Physics and Chemistry of Liquids, Vol. 41, 2003, p. 545.

[23] S. P. Verevkin, T. V. Vasiltsova, E. Bich, et al., "Thermodynamic Properties of Mixtures Containing Ionic Liquids: Activity Coefficients of Aldehydes and Ketones in 1-methyl-3-ethyl-imidazolium bis(trifluoromethyl-sulfonyl) Imide Using the Transpiration Method," Fluid Phase Equilibria, Vol. 218, No. 2, 2004, pp. 165-175.

[24] K.-S. Kim, B.-K. Shi, H. Lee, et al., "Refractive Index and Heat Capacity of 1-butyl-3-methylimidazolium Bromide and 1-butyl-3-methylimidazolium Tetrafluoroborate, and Vapor Pressure of Binary Systems for 1-butyl-3-me- 
thylimidazolium Bromide + Trifluoroethanol and 1-butyl3-methylimidazolium Tetrafluoroborate + Trifluoroethanol," rFluid Phase Equilibria, Vol. 218, No. 2, 2004, pp. 215-220.

[25] A. Shariati and C. J. Peters, "High-Pressure Phase Behavior of Systems with Ionic Liquids: Part III. The Binary System Carbon Dioxide + 1-hexyl-3-methylimidazolium Hexafluorophosphate," Journal of Supercritical Fluids, Vol. 30, No. 2, 2004, pp. 139-144.

[26] L. P. N. Rebelo, V. Najdanovic-Visak, Z. P. Visak, et al., "A Detailed Thermodynamic Analysis of $\left[\mathrm{C}_{4} \mathrm{mim}\right]\left[\mathrm{BF}_{4}\right]^{+}$ Water as a Case Study to Model Ionic Liquid Aqueous Solutions," Green Chemistry, Vol. 6, No. 8, 2004, pp. 369-381.

[27] K.-S. Kim, S. Y. Park, S. Choi, et al., "Vapor Pressures of the 1-butyl-3-methylimidazolium Bromide + Water, 1butyl-3-methylimidazolium Tetrafluoroborate + Water, and 1-(2-hydroxyethyl)-3-methylimidazolium Tetrafluoroborate + Water Systems," Journal of Chemical and Engineering Data, Vol. 49, No. 6, 2004, pp. 1550-1553.

[28] J. Zhao, C.-C. Dong, C.-X. Li, et al., "Isobaric VaporLiquid Equilibria for Ethanol-Water System Containing Different Ionic Liquids at Atmospheric Pressure," Fluid Phase Equilibria, Vol. 242, No. 2, 2006, pp. 147-153.

[29] J. Sararov, S. P. Verevkin, E. Bich, et al., "Vapor Pressures and Activity Coefficients of n-Alcohols and Benzene in Binary Mixtures with 1-methyl-3-butylimidazolium Octyl Sulfate and 1-methyl-3-octylimidazolium Tetrafluoroborate," Journal of Chemical and Engineering Data, Vol. 51, No. 2, 2006, pp. 518-525.

[30] K. Swiderski, A. McLean, C. M. Gordon, et al., "Estimates of Internal Energies of Vaporisation of Some Room Temperature Ionic Liquids," Chemical Communications, 2004, pp. 2178-2179.

[31] Y. U. Paulechka, G. J. Kabo, A. V. Blokhin, et al., "Thermodynamic Properties of 1-butyl-3-methylimidazolium Hexafluorophosphate in the Ideal Gas State," Journal of Chemical and Engineering Data, Vol. 48, No. 3, 2003, pp. 457-462.

[32] M. Yoshizawa, W. Xu and C. A. Angell, "Ionic Liquids by Proton Transfer: Vapor Pressure, Conductivity, and the Relevance of $\Delta \mathrm{pKa}$ from Aqueous Solutions," Journal of the American Chemical Society, Vol. 125, No. 50, 2003, pp. 15411-15419.

[33] U. P. Kreher, A. E. Rosamilia, C. L. Raston, et al., "Self-Associated, 'Distillable' Ionic Media," Molecules, Vol. 9, No. 6, 2004, pp. 387-393.

[34] H. Luo, G. A. Baker, J. S. Lee, et al., "Ultrastable Superbase-Derived Protic Ionic Liquids," Journal of Physical Chemistry B, Vol. 113, No. 13, 2009, pp. 4181-4183.

[35] L. P. N. Rebelo, J. N. C. Lopes, J. M. S. S. Esperança, et al., "On the Critical Temperature, Normal Boiling Point, and Vapor Pressure of Ionic Liquids," Journal of Physical Chemistry B, Vol. 109, No. 13, 2005, pp. 6040-6043.

[36] Y. U. Paulechka, D. H. Zaitsau, G. J. Kabo, et al., "Vapor Pressure and Thermal Stability of Ionic Liquid 1-butyl3-methylimidazolium bis(trifluoromethylsulfonyl)amide,"
Thermochimica Acta, Vol. 439, No. 1-2, 2005, pp. 158160.

[37] D. H. Zaitsau, G. J. Kabo, A. A. Strechan, et al., "Experimental Vapor Pressures of 1-alkyl-3-methylimidazolium bis(trifluoromethylsulfonyl)imides and a Correlation Scheme for Estimation of Vaporization Enthalpies of Ionic Liquids," Journal of Physical Chemistry A, Vol. 110, No. 22, 2006, pp. 7303-7306.

[38] M. J. Earle, J. M. S. S. Esperança, M. A. Gilea, et al., "The Distillation and Volatility of Ionic Liquids," Nature, Vol. 439, No. 7078, 2006, pp. 831-834.

[39] D. R. MacFarlane, J. M. Pringle, K. M. Johnsson, et al., "Lewis Base Ionic Liquids," Chemical Communications, 2006, pp. 1905-1917.

[40] P. Anastas and J. Warner, "Green Chemistry-Theory and Practice," Oxford University Press, US, 2002.

[41] B. Jastorff, R. Störmann, J. Ranke, et al., "How Hazardous are Ionic Liquids? Structure-Activity Relationships and Biological Testing as Important Elements for Sustainability Evaluation," Green Chemistry, Vol. 5, No. 2, 2003, pp. 136-142.

[42] J. Ranke, K. Mölter, F. Stock, et al., "Biological Effects of Imidazolium Ionic Liquids with Varying Chain Lengths in Acute Vibrio Fischeri and WST-1 Cell Viability Assays," Ecotoxicology and Environmental Safety, Vol. 58, No. 3, 2004, pp. 396-404.

[43] K. M. Docherty and C. F. Kulpa Jr., "Toxicity and Antimicrobial Activity of Imidazolium and Pyridinium Ionic Liquids," Green Chemistry, Vol. 7, No. 4, 2005, pp. 185189.

[44] P. Stepnowski, A. C. Skladanowski, A. Ludwiczak, et al., "Evaluating the Cytotoxicity of Ionic Liquids Using Human Cell Line Hela," Human \& Experimental Toxicology, Vol. 23, No. 11, 2004, pp. 513-517.

[45] M. Matsumoto, K. Mochiduki, K. Fukunishi, et al., "Extraction of Organic Acids Using Imidazolium-Based Ionic Liquids and their Toxicity to Lactobacillus Rhamnosus," Separation and Purification Technology, Vol. 40, No. 1, 2004, pp. 97-101.

[46] M. Matsumoto, K. Mochiduki and K. Kondo, "Toxicity of Ionic Liquids and Organic Solvents to Lactic AcidProducing Bacteria," Journal of Bioscience and Bioengineering, Vol. 98, No. 5, 2004, pp. 344-347.

[47] F. Ganske and U. Bornscheuer, "Growth of Escherichia coli, Pichia pastoris and Bacillus cereus in the Presence of the Ionic Liquids $[\mathrm{BMIM}]\left[\mathrm{BF}_{4}\right]$ and $[\mathrm{BMIM}]\left[\mathrm{PF}_{6}\right]$ and Organic Solvents," Biotechnology Letters, Vol. 28, No. 7, 2006, pp. 465-469.

[48] R. P. Swatloski, J. D. Holbrey, S. B. Memon, et al., "Using Caenorhabditis Elegans to Probe Toxicity of 1-alkyl3-methylimidazolium Chloride Based Ionic Liquids," Chemical Communications, 2004, pp. 668-669.

[49] F. Stock, J. Hoffmann, J. Ranke, et al., "Effects of Ionic Liquids on the Acetylcholinesterase-A Structure-Activity Relationship Consideration," Green Chemistry, Vol. 6, No. 6, 2004, pp. 286-290. 
[50] A. Latała, P. Stepnowski, M. Nędzi, et al., "Marine Toxicity Assessment of Imidazolium Ionic Liquids: Acute Effects on the Baltic Algae Oocystis Submarina and Cyclotella Meneghiniana," Aquatic Toxicology, Vol. 73, No. 1, 2005, pp. 91-98.

[51] R. J. Bernot, M. A. Brueseke, M. A. Evans-White, et al., "Acute and Chronic Toxicity of Imidazolium-Based Ionic Liquids on Daphnia Magna," Environmental Toxicology and Chemistry, Vol. 24, No. 1, 2005, pp. 87-92.

[52] C. Pretti, C. Chiappe, D. Pieraccini, et al., "Acute Toxicity of Ionic Liquids to the Zebrafish (Danio Rerio)," Green Chemistry, Vol. 8, No. 3, 2006, pp. 238-240.

[53] T. D. Landry, K. Brooks, D. Poche, et al., "Acute Toxicity Profile of 1-butyl-3-methylimidazolium Chloride," Bulletin of Environmental Contamination and Toxicology, Vol. 74, 2005, pp. 559.

[54] R. J. Bernot, E. E. Kennedy and G. A. Lamberti, "Effects of Ionic Liquids on the Survival, Movement, and Feeding Behavior of the Freshwater Snail, Physa Acuta," Environmental Toxicology \& Chemistry, Vol. 24, 2005, p. 1759.

[55] D. M. Costello, L. M. Brown and G. A. Lamberti, "Acute Toxic Effects of Ionic Liquids on Zebra Mussel (Dreissena polymorpha) Survival and Feeding," Green Chemistry, Vol. 11, No. 4, 2009, pp. 548-553.

[56] D. J. Couling, R. J. Bernot, K. M. Docherty, et al., "Assessing the Factors Responsible for Ionic Liquid Toxicity to Aquatic Organisms via Quantitative Structure-Property Relationship Modeling," Green Chemistry, Vol. 8, No. 1, 2006, pp. 82-90.

[57] P. Stepnowski and P. Storoniak, "Lipophilicity and Metabolic Route Prediction of Imidazolium Ionic Liquids," Environmental Science and Pollution Research, Vol. 12, No. 4, 2005, pp. 199-204.

[58] N. Gathergood, M. T. Garcia and P. J. Scammells, "Biodegradable Ionic Liquids: Part I. Concept, Preliminary Targets and Evaluation," Green Chemistry, Vol. 6, No. 3, 2004, pp. 166-175.

[59] S. Kumar, W. Ruth, B. Sprenger, et al., "On the Biodegradation of Ionic Liquid 1-butyl-3-methylimidazolium tetrafluoroborate," Chimica Oggi, Vol. 24, No. 2, 2006, pp. 24-26.

[60] G.-H. Tao, L. He, N. Sun, et al., "New Generation Ionic Liquids: Cations Derived from Amino Acids," Chemical Communications, 2005, pp. 3562-3564.

[61] B. Ni, A. D. Headley and G. Li, "Design and Synthesis of C-2 Substituted Chiral Imidazolium Ionic Liquids from Amino Acid Derivatives," Journal of Organic Chemistry, Vol. 70, No. 25, 2005, pp. 10600-10602.

[62] P. Wasserscheid, A. Bösmann and C. Bolm, "Synthesis and Properties of Ionic Liquids Derived from the Chiral Pool," Chemical Communications, 2002, pp. 200-201.

[63] W. Bao, Z. Wang and Y. Li, "Synthesis of Chiral Ionic Liquids from Natural Amino Acids," Journal of Organic Chemistry, Vol. 68, No. 2, 2003, pp. 591-593.

[64] E. B. Carter, S. L. Culver, P. A. Fox, et al., "Sweet Suc- cess: Ionic Liquids Derived from Non-Nutritive Sweeteners," Chemical Communications, 2004, pp. 630-631.

[65] N. Gathergood and P. J. Scammells, "Design and Preparation of Room-Temperature Ionic Liquids Containing Biodegradable Side Chains," Australian Journal of Chemistry, Vol. 55, No. 9, 2002, pp. 557-560.

[66] P. J. Scammells, J. L. Scott and R. D. Singer, "Ionic Liquids: The Neglected Issues," Australian Journal of Chemistry, Vol. 58, No. 3, 2005, pp. 155-169.

[67] N. Gathergood, P. J. Scammells and M. T. Garcia, "Biodegradable Ionic Liquids: Part III. The First Readily Biodegradable Ionic Liquids," Green Chemistry, Vol. 8, No. 2, 2006, pp. 156-160.

[68] M. T. Garcia, N. Gathergood and P. J. Scammells, "Biodegradable Ionic Liquids: Part II. Effect of the Anion and Toxicology," Green Chemistry, Vol. 7, No. 1, 2005, pp. 9-14.

[69] J. R. Harjani, R. D. Singer, M. T. Garcia, et al., "Biodegradable Pyridinium Ionic Liquids: Design, Synthesis and Evaluation," Green Chemistry, Vol. 11, No. 1, 2009, pp. 83-90.

[70] Y. Fan, M. Chen, C. Shentu, et al., "Ionic liquids Extraction of Para Red and Sudan Dyes from Chilli Powder, Chilli Oil and Food Additive Combined with High Performance Liquid Chromatography," Analytica Chimica Acta, Vol. 650, 2009, p. 66

[71] A. Martín-Calero, V. Pino, J. H. Ayala, et al., "Ionic Liquids as Mobile Phase Additives in High-Performance Liquid Chromatography with Electrochemical Detection: Application to the Determination of Heterocyclic Aromatic Amines in Meat-Based Infant Foods," Talanta, Vol. 79, No. 3, 2009, pp. 590-597.

[72] J. L. Manzoori, M. Amjad and J. Abulhassani, "UltraTrace Determination of Lead in Water and Food Samples by Using Ionic Liquid-Based Single Drop Microextraction-Electrothermal Atomic Absorption Spectrometry," Analytica Chimica Acta, Vol. 644, No. 1-2, 2009, pp. 48-52.

[73] M. Matzke, S. Stolte, J. Arning, et al., "Ionic Liquids in Soils: Effects of Different Anion Species of Imidazolium Based Ionic Liquids on wheat (Triticum Aestivum) as Affected by Different Clay Minerals and Clay Concentrations," Ecotoxicology, Vol. 18, No. 2, 2009, pp. 197-203.

[74] A. Latała, M. Nędzi and P. Stepnowski, "Toxicity of Imidazolium and Pyridinium Based Ionic Liquids towards Algae. Chlorella vulgaris, Oocystis submarina (green algae) and Cyclotella meneghiniana, Skeletonema marinoi (diatoms)," Green Chemistry, Vol. 11, No. 4, 2009, pp. 580-588.

[75] M. Matzke, K. Thiele, A. Mueller, et al., "Sorption and Desorption of Imidazolium Based Ionic Liquids in Different Soil Types," Chemosphere, Vol. 74, No. 4, 2009, pp. 568-574.

[76] M. Rebros, H. Q. N. Gunaratne, J. Ferguson, et al., "A High throughput Screen to Test the Biocompatibility of Water-Miscible Ionic Liquids," Green Chemistry, Vol. 11, 
No. 3, 2009, pp. 402-408.

[77] G. Turian, "Polarity: From Electromagnetic Origins to Biological Take-Over," Hamburg Kovač, 1994.

[78] A. J. Carmichael and K. R. Seddon, "Polarity Study of Some 1-alkyl-3-methylimidazolium Ambient-Temperature Ionic Liquids with the Solvatochromic Dye, Nile Red," Journal of Physical Organic Chemistry, Vol. 13, 2000, p. 591.

[79] S. N. V. K. Aki, J. F. Brennecke and A. Samanta, "How Polar are Room-Temperature Ionic Liquids?" Chemical Communications, 2001, pp. 413-414.

[80] P. K. Mandal and A. Samnta, "Fluorescence Studies in a Pyrrolidinium Ionic Liquid: Polarity of the Medium and Solvation Dynamics," Journal of Physical Chemistry B, Vol. 109, No. 31, 2005, pp. 15172-15177.

[81] A. Kawai, T. Hidemori and K. Shibuya, "Polarity of Room-Temperature Ionic Liquid as Examined by EPR Spectroscopy," Chemistry Letters, Vol. 33, No. 11, 2004, pp. 1464-1465.

[82] G. Angelini, C. Chiappe, P. D. Maria, et al., "Determination of the Polarities of Some Ionic Liquids Using 2-nitrocyclohexanone as the Probe," Journal of Organic Chemistry, Vol. 70, No. 20, 2005, pp. 8193-8196.

[83] C. Wakai, A. Oleinikova, M. Ott, et al., "How Polar are Ionic Liquids? Determination of the Static Dielectric Constant of an Imidazolium-Based Ionic Liquid by Microwave Dielectric Spectroscopy," Journal of Physical Chemistry B, Vol. 109, No. 36, 2005, pp. 17028-17030.

[84] G.-H. Tao, M. Zou, X.-H. Wang, et al., "Comparison of Polarities of Room-Temperature Ionic Liquids Using FT-IR Spectroscopic Probes," Australian Journal of Chemistry, Vol. 58, No. 5, 2005, pp. 327-331.

[85] T. Köddermann, C. Wertz, A. Heintz, et al., "The Association of Water in Ionic Liquids: A Reliable Measure of Polarity," Angewandte Chemie International Edition, Vol. 45, No. 22, 2006, pp. 3697-3702.

[86] C. Reichardt, "Polarity of Ionic Liquids Determined Empirically by Means of Solvatochromic Pyridinium NPhenolate Betaine Dyes," Green Chemistry, Vol. 7, No. 5, 2005, pp. 339-351.

[87] P. J. Dyson, G. Laurenczy, C. A. Ohlin, et al., "Determination of Hydrogen Concentration in Ionic Liquids and the Effect (or Lack of) on Rates of Hydrogenation," Chemical Communications, 2003, pp.2418-2419.

[88] C. A. Ohlin, P. J. Dyson and G. Laurenczy, "Carbon Monoxide Solubility in Ionic Liquids: Determination, Prediction and Relevance to Hydroformylation," Chemical Communications, 2004, pp. 1070-1071.

[89] H. Liu, G.-H. Tao, D. G. Evans, et al., "Solubility of $\mathrm{C}_{60}$ in Ionic Liquids," Carbon, Vol. 43, No. 8, 2005, pp. 1782-1785.

[90] Y. Kou, W. Xiong, G. Tao, et al., "Absorption and Capture of Methane into Ionic Liquid," Journal of Natural Gas Chemistry, Vol. 15, No. 4, 2006, pp. 282-286.

[91] P. Wasserscheid, C. M. Dordon, C. Hilgers, et al., "Ionic Liquids: Polar, but Weakly Coordinating Solvents for the
First Biphasic Oligomerisation of Ethene to Higher -olefins with Cationic Ni Complexes," Chemical Communications, 2001, pp. 1186.

[92] A.-V. Mudering, A. Babai, S. Arenz, et al., "The "Noncoordinating" Anion $\mathrm{Tf}_{2} \mathrm{~N}^{-}$Coordinates to $\mathrm{Yb}^{2+}$ : A Structurally Characterized $\mathrm{Tf}_{2} \mathrm{~N}^{-}$Complex from the Ionic Liquid $[\mathrm{mppyr}]\left[\mathrm{Tf}_{2} \mathrm{~N}\right]$," Angewandte Chemie International Edition, Vol. 44, No. 34, 2005, pp. 5485-5488.

[93] D. B. Williams, M. E. Stoll, B. L. Scott, et al., "Coordination Chemistry of the bis(trifluoromethylsulfonyl)imide Anion: Molecular Interactions in Room Temperature Ionic Liquids," Chemical Communications, 2005, pp. 1438-1440.

[94] A. Babai and A.-V. Mudering, "Crystal Engineering in Ionic Liquids. The Crystal Structures of $[\mathrm{Mppyr}]_{3}\left[\mathrm{NdI}_{6}\right]$ and $[\mathrm{Bmpyr}]_{4}\left[\mathrm{NdI}_{6}\right]\left[\mathrm{Tf}_{2} \mathrm{~N}\right]$," Inorganic Chemistry, Vol. 45, No. 13, 2006, pp. 4874-4876.

[95] R. J. P. Williams and R. D. Gillard, "Coordination Chemistry and Analysis," Pergamon Press, Oxford, 1987.

[96] P. Wasserscheid and E. T. Welton, "Ionic Liquids in Synthesis," Wiley-VCH verlag GmbH \& Co. KGaA, 2002.

[97] A. G. Avent, P. A. Chaloner, M. P. Day, et al., "Evidence for Hydrogen Bonding in Solutions of 1-ethyl-3-methylimidazolium Halides, and its Implications for Room-Temperature Halogenoaluminate(III) Ionic Liquids," Journal of the Chemical Society Dalton Transactions, 1994, pp. 3405-3413.

[98] A. Elaiwi, P. B. Hitchcock, K. R. Seddon, et al., "Hydrogen Bonding in Imidazolium Salts and its Implications for Ambient-Temperature Halogenoaluminate(III) Ionic Liquids," Journal of the Chemical Society Dalton Transactions, 1995, pp. 3467-3472.

[99] A. R. Choudhury, N. Winterton, A. Steiner, et al., "In Situ Crystallization of Low-Melting Ionic Liquids," Journal of the American Chemical Society, Vol. 127, 2005, pp. 16792-16793.

[100] A. R. Katritzky, H. Yang, D. Zhang, et al., "Strategies toward the Design of Energetic Ionic Liquids: Nitro- and Nitrile-Substituted N,N-dialkylimidazolium Salts," New Journal of Chemistry, Vol. 30, No. 3, 2006, pp. 349-358.

[101] D. J. Tempel, P. B. Henderson, J. R. Brzozowski, et al., "Liquid Media Containing Lewis Acidic Reactive Compounds for Storage and Delivery of Lewis Basic Gases," U.S. Pat. Appl. Publ., 2005.US 2005276733.

[102] D. R. Graham, D. J. Tempel, B. A. Toseland, et al., "Storage and Delivery Systems for Gases Held in Liquid Medium," European Patent Applications, 2006.EP 161495.

[103] Z. Fei, D. Zhao, T. J. Geldbach, et al., "Structure of Nitrile-Functionalized Alkyltrifluoroborate Salts," European Journal of Organic Chemistry, Vol. 2005, No. 5, 2005, pp. 860-865.

[104]Z. Fei, D. Zhao, R. Scopelliti, et al., "Organometallic Complexes Derived from Alkyne-Functionalized Imidazolium Salts," Organometallics, Vol. 23, No. 7, 2004, pp. 1622-1628.

[105] D. Zhao, Z. Fei, R. Scopelliti, et al., "Synthesis and 
Characterization of Ionic Liquids Incorporating the Nitrile Functionality," Inorganic Chemistry, Vol. 43, No. 6, 2004, pp. 2197-2205.

[106] D. Zhao, Z. Fei, C. A. Ohlin, et al., "Dual-Functionalised Ionic Liquids: Synthesis and Characterisation of Imidazolium Salts with a Nitrile-Functionalised Anion," Chemical Communications, 2004, pp. 2500-2501.

[107] Z. J. Karpinski and R. A. Osteryoung, "Determination of Equilibrium Constants for the Tetrachloroaluminate Ion Dissociation in Ambient-Temperature Ionic Liquids," Inorganic Chemistry, Vol. 23, No. 10, 1984, pp. 1491-1493.

[108] J. L. E. Campbell and K. E. Johnson, "The Chemistry of Protons in Ambient-Temperature Ionic Liquids: Solubility and Electrochemical Profiles of $\mathrm{HCl}$ in $\mathrm{HCl}: \mathrm{ImCl}$ : $\mathrm{AlCl}_{3}$ Ionic Liquids as a Function of Pressure (295 K)," Journal of the American Chemical Society, Vol. 117, No. 29, 1995, pp. 7791-7800.

[109] R. P. Swatloski, J. D. Holbrey and R. D. Rogers, "Ionic Liquids are not Always Green: Hydrolysis of 1-butyl-3methylimidazolium Hexafluorophosphate," Green Chemistry, Vol. 5, No. 4, 2003, pp. 361-363.

[110] A. Basso, S. Cantone, P. Linda, et al., "Stability and Activity of Immobilised Penicillin G Amidase in Ionic Liquids at controlled $\mathrm{a}_{\mathrm{w}}$," Green Chemistry, Vol. 7, No. 9, 2005, pp. 671-676.

[111] J. Li, Y. Shen, Y. Zhang, et al., "Room-Temperature Ionic Liquids as Media to Enhance the Electrochemical Stability of Self-Assembled Monolayers of Alkanethiols on Gold Electrodes," Chemical Communications, Vol. 3, 2005 , pp. 360.

[112] A. Horváth, "Michael Adducts in the Regioselective Synthesis of N-Substituted Azoles," Synthesis, 1995, pp. 1183-1189.

[113] T. Ramnial, D. D. Ino and J. A. C. Clyburne, "Phosphonium Ionic Liquids as Reaction Media for Strong Bases," Chemical Communications, 2005, pp. 325-327.

[114] J. L. Anderson, R. Ding, A. Ellern, et al., "Structure and Properties of High Stability Geminal Dicationic Ionic Liquids," Journal of the American Chemical Society, Vol. 127, No. 2, 2005, pp. 593-604.

[115] G. Drake, T. Hawkins, A. Brand, et al., "Energetic, Low-Melting Salts of Simple Heterocycles," Propellants Explosives Pyrotechnics, Vol. 28, No. 4, 2003, pp. 174.
[116] W. Oihara, M. Yoshizawa and H. Ohno, "Novel Ionic Liquids Composed of Only Azole Ions," Chemistry Letters, Vol. 33, No. 8, 2004, pp. 1022-1023.

[117] H. Ohno, M. Yoshizawa, W. Ogiwara, et al., "IONIC LIQUID,” Japan Patent, 2004.JP 2004331521.

[118] A. R. Katrizky, S. Singh, K. Kirichenko, et al., "1-butyl-3-methylimidazolium 3,5-dinitro-1,2,4-triazolate: A Novel Ionic Liquid Containing a Rigid, Planar Energetic Anion," Chemical Communications, 2005, pp. 868870.

[119] A. R. Katritzky, S. Singh, K. Kirichenko, et al., "In search of Ionic Liquids Incorporating Azolate Anions," Chemistry - A European Journal, Vol. 12, No. 17, 2006, pp. 4630-4641.

[120] H. Xue, S. W. Arritt, B. Twamley, et al., "Energetic Salts from N-Aminoazoles," Inorganic Chemistry, Vol. 43, No. 25, 2004, pp. 7972-7977.

[121] H. Xue, Y. Gao, B. Twamley, et al., "Energetic Azolium Azolate Salts," Inorganic Chemistry, Vol. 44, No. 14, 2005, pp. 5068-5072.

[122] H. Xue, B. Twamley and J. M. Shreeve, "Energetic Quaternary Salts Containing bi(1,2,4-triazoles)," Inorganic Chemistry, Vol. 44, No. 20, 2005, pp. 7009-7013.

[123] M. W. Schmidt, M. S. Gordon and J. A. Boatz, "Triazolium-Based Energetic Ionic Liquids," Journal of Physics and Chemistry A, Vol. 109, No. 32, 2005, pp. 7285-7295.

[124] R. P. Singh, R. D. Verma, D. T. Meshri, et al., "Energetic Nitrogen-Rich Salts and Ionic Liquids," Angewandte Chemie International Edition, Vol. 45, No. 22, 2006, pp. 3584-3601.

[125] M. Smiglak, W. M. Reichert, J. D. Holbrey, et al., "Combustible Ionic Liquids by Design: Is Laboratory Safety Another Ionic Liquid Myth?" Chemical Communications, 2006, pp. 2554-2556. 
